\title{
Aspecto físico-químico e bacteriológico da hidrologia subterrânea na região do depósito de resíduos sólidos urbanos, Londrina, Paraná, Brasil.
}

\author{
Physical-chemical and bacteriological aspects of the groundwater in the \\ sanitary landfills in the metropolitan region of Londrina, Paraná, Brazil
}

\author{
Luciana T. Mendes ${ }^{1}$; João de Sousa Costa ${ }^{2}$ Eliana França ${ }^{3}$; Raquel Teixeira ${ }^{4}$; Deize \\ Dias Lopes ${ }^{5}$; Sandra Márcia Cesário P. da Silva ${ }^{6}$; João Carlos Alves \\ Luiz Henrique Dall’Antonia ${ }^{8}$
}

\begin{abstract}
Resumo
Um estudo da qualidade físico-química e bacteriológica da água subterrânea na região do Depósitos de Resíduos Sólidos Urbano de Londrina PR foi realizado por meio do monitoramento de doze poços que atingem o lençol subterrâneo e também do afloramento do lençol no Rio Periquitos. Os resultados das análises das 120 amostras de águas coletadas foram comparados aos valores máximos permissíveis para consumo humano, segundo a legislação federal vigente. Foram encontrados coliformes totais entre $3,1 \mathrm{NMP} / 100 \mathrm{~mL}$ (Poço 4) e 120330 NMP/100mL (Rio Periquitos) e, coliformes fecais entre 0 e 4100 NMP/ $100 \mathrm{~mL}$ (Rio Periquitos), valores associados à devido ao fato de animais de propriedades vizinhas alimentarem-se na região. $\mathrm{O}$ pH, turbidez, DQO e DBO estavam dentro dos valores esperados, exceto pela condutividade que mostrou-se alterada.
\end{abstract}

Palavras-chave: Aterro sanitário. Hidrologia. Contaminação.

\begin{abstract}
A detailed study of the physical-chemical and bacteriological qualities of the subterranean water at sanitary landfills in the Metropolitan Region of Londrina (PR), was carried out. The field of twelve wells that reach the groundwater as well as the emergence of the watertable of the Periquitos River, were also monitored. The results of the analyses of 120 samples of the collected water were compared to the permissible maximum values for human consumption

\footnotetext{
${ }^{1}$ Bacharel em Química - Laboratório de Eletroquímica e Materiais/Depto. Química /CCE/UEL

${ }^{2}$ Bacharel em Química - Laboratório de Eletroquímica e Materiais/Depto. Química /CCE/UEL

${ }^{3}$ Bacharel em Química - Laboratório de Saneamento/Depto. Construção Civil /CTU/UEL

${ }^{4}$ Professora Assistente - Laboratório de Geotecnia/Depto. Construção Civil /CTU/UEL

${ }^{5}$ Professora Adjunta - Laboratório de Saneamento/Depto. Construção Civil /CTU/UEL

${ }^{6}$ Professora Associada - Laboratório de Saneamento/Depto. Construção Civil /CTU/UEL

${ }^{7}$ Professor Associado - Laboratório de Eletroquímica e Materiais/Depto. Química /CCE/UEL

${ }^{8}$ Professor Adjunto - Laboratório de Eletroquímica e Materiais/Depto. Química /CCE/UEL. e-mail: luizh@uel.br
} 
Mendes, L. T.; Costa J. S.; França, E.; Teixeira, R.; Lopes, D. D.; Silva, S. M. C. P.; Alves, J. C.; Dall'Antonia, L. H.

according to the Federal Legislation in Brazil. Total excrements were found around 3,1 NMP/100mL (Well 4) and 120330 NMP/100mL (Periquitos River) and fecal matter between 0 and $4100 \mathrm{NMP} / 100 \mathrm{~mL}$ (Periquitos River). Such values were associated to the contamination caused by the presence of animals from neighbor properties, feeding themselves in that region. The $\mathrm{pH}$, turbidity, $\mathrm{COD}$ and $\mathrm{BOD}$ were among the values expected, except for the conductivity that showed to be altered.

Key words: Sanitary landfill. Hydrology. Contamination

\section{Introdução}

A implantação de aterros sanitários consiste numa técnica bastante eficiente, que tem como objetivo melhorar a disposição final do lixo da cidade. Embora simples, essa técnica necessita de alguns cuidados em seu processo operacional, para que a sua eficiência seja maximizada. A operação incorreta de um aterro sanitário pode lhe conferir características indesejáveis, como sérios riscos à saúde e ao meio ambiente.

Como no processo de decomposição de resíduos sólidos ocorre a liberação de gases e líquidos (chorume ou líquidos percolados) muito poluentes, são exigidos cuidados como impermeabilização do solo, implantação de sistemas de drenagem eficazes, entre outros, para evitar uma possível contaminação da água, do solo e do ar.

O monitoramento de águas superficiais ou do lençol freático pode ser um bom método para avaliar a eficiência do aterro em relação a sua operação e ao controle ambiental. Esse monitoramento é feito por meio da coleta de amostras nos poços instalados no aterro. Vários parâmetros devem ser analisados para uma melhor compreensão da qualidade da água, e dentre podem ser destacados: $\mathrm{pH}$, condutividade, demanda bioquímica de oxigênio (DBO), demanda química de oxigênio (DQO), nitratos e coliformes fecais, além de alguns metais como o chumbo, cádmio, ferro e manganês (COMPANHIA DE TECNOLOGIA E SANEAMENTO AMBIENTAL - CETESB, 2001)
A localização estratégica e a construção racional dos poços de monitoramento, aliadas aos métodos eficientes de coleta, além do acondicionamento e análise de amostras, permitem resultados bastante precisos acerca da influência do método de disposição dos resíduos na qualidade da água subterrânea (COMPANHIA DE TECNOLOGIA E SANEAMENTO AMBIENTAL - CETESB, 2001).

A partir das considerações acima, buscou-se avaliar a qualidade da água do aterro sanitário verificando a contaminação e eficiência do mesmo durante os anos de 2004 e 2005.

\section{Parte Experimental}

As amostras foram coletadas no aterro sanitário da cidade de Londrina-PR, que possui aproximadamente 488287 habitantes, conforme dados do IBGE (2000). $\mathrm{O}$ aterro possui uma área total de $135.000 \mathrm{~m}^{2}$, recebe diariamente 350 toneladas de lixo comum e está a aproximadamente $9 \mathrm{Km}$ do centro da cidade. $\mathrm{O}$ local pertence à bacia do Rio Tibagi e a 700 metros de distância do terreno ocupado pelos resíduos sólidos está localizada a nascente do córrego Periquitos, afluente do rio Tibagi.

Atualmente existem perfurados no aterro, doze poços de monitoramento (Figura 1), de profundidades variáveis, mas somente dez deles estão ativos, pois dois deles (poços 6 e 9) não apresentaram água, mesmo após períodos chuvosos. 
Aspecto físico-químico e bacteriológico da hidrologia subterrânea na região do depósito de resíduos sólidos urbanos, Londrina, Paraná, Brasil.

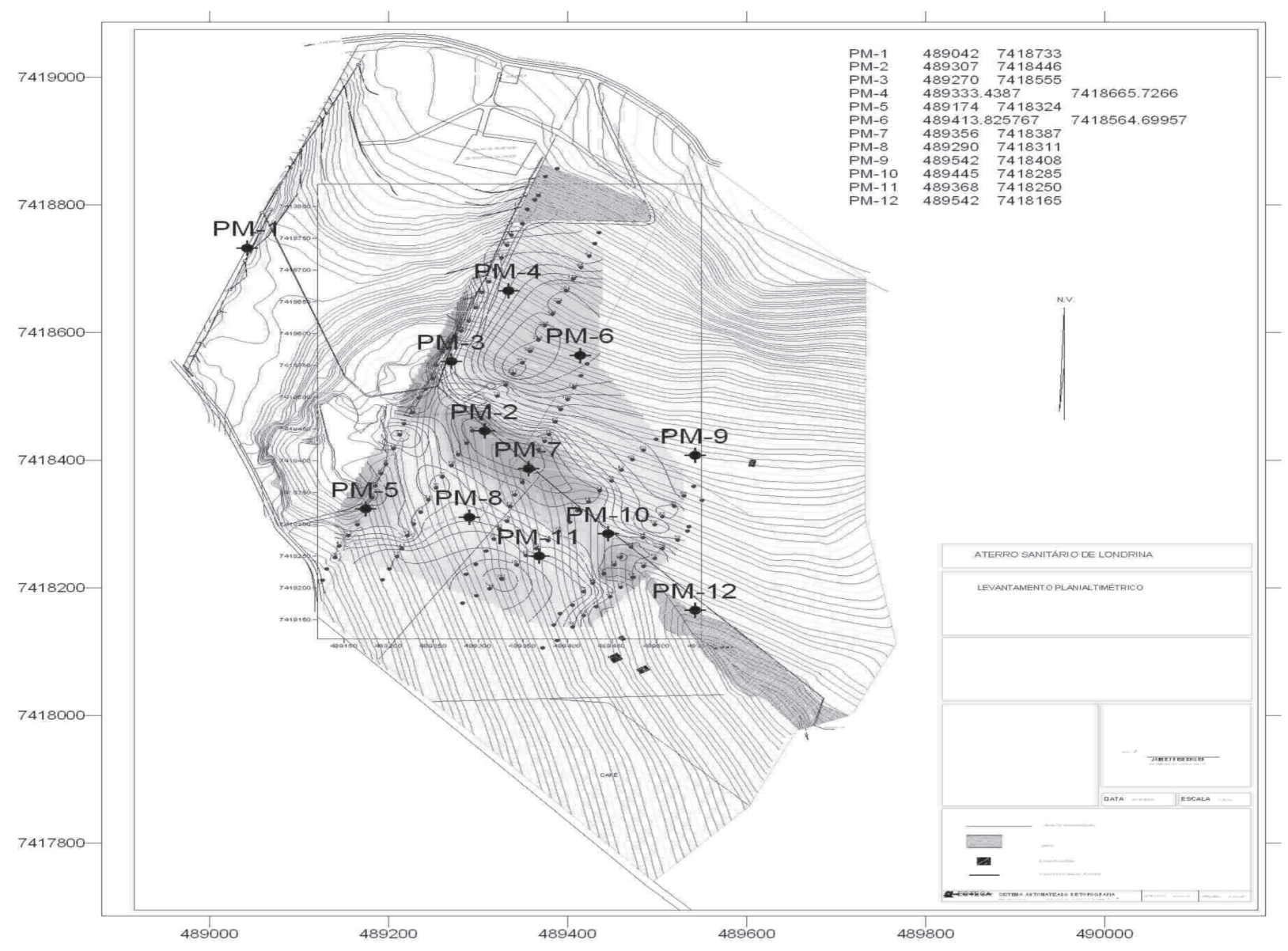

Figura 01 - Mapa do Aterro Sanitário de Londrina indicando os poços de perfuração e suas respectivas coordenadas para coleta de águas subterrâneas

Coleta de amostras

Uma vez que a água acumulada no poço pode não ser representativa da qualidade da água local, foi necessário à remoção desta, de tal forma que a água da formação fosse trocada. É importante utilizar uma técnica adequada de esgotamento de poços, para que não haja comprometimento da qualidade da água. Após o esgotamento e assim que o poço foi recuperado foi feita a coleta da amostra. Os primeiros parâmetros avaliados foram o $\mathrm{pH}$, temperatura e condutividade medidos no local.

A fim de reduzir as possibilidades de contaminação da amostra, utilizou-se um amostrador específico (beiler) para cada poço. Os frascos foram lavados com detergente (preferencialmente não-fosfatado) água de torneira e enxaguados com água destilada.
Uma alternativa é o emprego de solução de ácido crômico para remoção de depósitos orgânicos.

Para a realização de testes microbiológicos, as amostras foram coletadas, com o uso de luvas cirúrgicas, em frascos esterilizados (VON SPERLING, 1996).

Muitos dos constituintes químicos e parâmetros físico-químicos que devem ser medidos ou avaliados em programas de monitoramento não são quimicamente estáveis, assim as amostras foram armazenadas a $0{ }^{\circ} \mathrm{C}$. $\mathrm{O}$ armazenamento a baixas temperaturas tem o objetivo de retardar a ação biológica, a hidrólise e reduzir os efeitos de sorção. 
Mendes, L. T.; Costa J. S.; França, E.; Teixeira, R.; Lopes, D. D.; Silva, S. M. C. P.; Alves, J. C.; Dall'Antonia, L. H.

Foram realizadas coletas no período de junho/2004 a novembro/2005, principalmente nos períodos de estiagem seguidos por uma estação chuvosa (Figura 2). Os testes físico-químicos e microbiológicos foram realizados no Laboratório de Saneamento da Universidade Estadual de Londrina, conforme o Standard Methods for Examination of Water and Wastewater (GREENBERG; CONNORS; JENKIS, 1992).

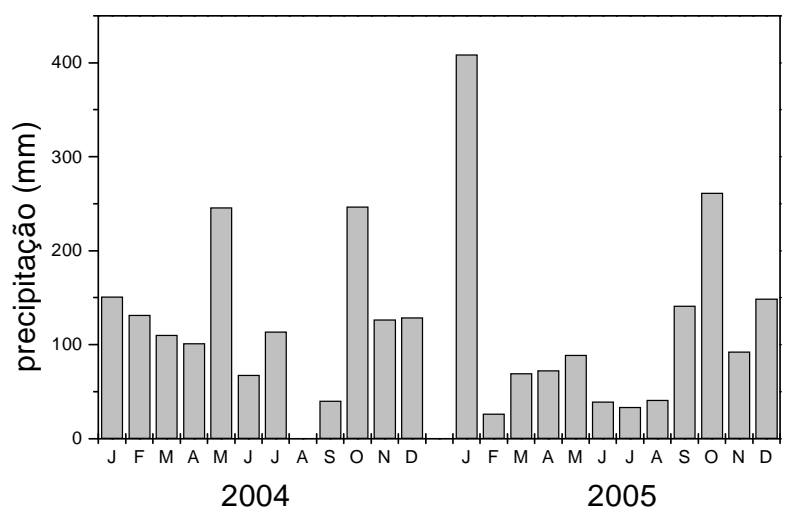

Figura 02 - Precipitação pluviométrica na cidade de Londrina, PR, no período 2004 a 2005 (Dadosfornecidos pelo Instituto Agronômico do Paraná, IAPAR)

\section{Procedimento Experimental}

\section{Potencial hidrogeniônico $(p H)$}

$\mathrm{O}$ pH de cada amostra foi medido utilizando-se um pHmetro HANNA Instruments - Modelo HI 9321, após calibração em solução tampão em pH 4 e 7 .

\section{Condutividade}

A condutividade de cada amostra foi medida utilizando-se um condutivímetro Tecnopon - MCA 150. Após a calibração do aparelho com solução padrão fornecida pelo fabricante, as leituras das amostras foram realizadas a temperatura ambiente.

\section{Coloração}

Cada uma das amostras foi colocada em um tubo de Nessler e levada a um equipamento Aqua-tester NESSLER QUANTI - 200, fazendo uma comparação de cor com os discos colorimétricos. Junto com o tubo que continha a amostra, foi colocado também um tubo contendo água destilada que foi usado como branco.

\section{Turbidez}

As leituras de turbidez foram realizadas em Turbidímetro HACH - 2100P com leituras em escalas de 10,100 e 1000 NTU previamente calibrado e estabilizado. A amostra foi transferida para uma cubeta padrão, e limpa com um tecido. Em seguida, foi conectada a abertura do equipamento e as leituras foram realizadas à temperatura ambiente.

\section{Alcalinidade}

Alíquotas de $100 \mathrm{~mL}$ das amostras de águas dos poços foram tituladas com ácido sulfúrico $(0,0308 \mathrm{~N}$ e 0,191N) até pH 5,7 (alcalinidade à bicarbonato) e pH 4,3 (alcalinidade à carbonato). Um pHmetro HANNA Instruments - Modelo HI 9321 foi utilizado após calibração com soluções tampão pH 4 e 7.

\section{Demanda bioquímica de oxigênio (DBO)}

Com o medidor de oxigênio dissolvido, mediu-se o oxigênio presente inicialmente em cada amostra diluída previamente em água de diluição (água composta de nutrientes necessários para a sobrevivência dos microorganismos consumidores de oxigênio). As amostras foram incubadas à temperatura de $\pm 20^{\circ} \mathrm{C}$. Após cinco dias, foram realizadas novas leituras para determinação da quantidade de oxigênio que foi consumido $\left(\mathrm{DBO}_{5,20}\right)$.

$\mathrm{O}$ medidor de oxigênio foi calibrado em $0 \%$ de oxigênio com uma solução preparada a partir da dissolução de 2,0 g de sulfito de sódio em $200 \mathrm{ml}$ de água. Para a calibração em $100 \%$, preparou-se uma solução com $1 \mathrm{ml}$ de sulfato manganoso, $1 \mathrm{ml}$ de azida sódica e $1 \mathrm{ml}$ de ácido sulfúrico concentrado e titulouse com tiossulfato de sódio utilizando amido como indicador. $\mathrm{O}$ volume gasto vezes 2 foi a concentração de $\mathrm{O}_{2}$ dissolvido e a leitura foi realizada em $100 \%$ do aparelho.

$$
\begin{gathered}
\text { A DBO é calculada pela equação, } \\
D B O_{5.20}\left(m g O_{2} / L\right)=\frac{O D_{\text {inicial }}-O D_{\text {final }}}{\rho} \text {,onde } \rho
\end{gathered}
$$


é a fração volumétrica decimal de amostra $(\mathrm{mL}$ de amostra/volume do frasco). $\mathrm{DBO}_{5.20}$ é a referência que se usa para o valor de DBO encontrado em 5 dias de incubação a $20^{\circ} \mathrm{C}$.

\section{Demanda química de oxigênio $(D Q O)$}

Em balões de fundo chato de $250 \mathrm{~mL}$ foram adicionados, na sequiência, $0,4 \mathrm{~g}$ de sulfato de mercúrio, $25 \mathrm{ml}$ de ácido sulfúrico concentrado com sulfato de prata $\left(\mathrm{H}_{2} \mathrm{SO}_{4}-\mathrm{Ag}_{2} \mathrm{SO}_{4}\right)$ previamente preparado, $25 \mathrm{ml} \mathrm{de}$ dicromato de potássio $0,25 \mathrm{~N}, 50 \mathrm{~mL}$ da amostra e mais $50 \mathrm{ml}$ de ácido sulfúrico concentrado com sulfato de prata com algumas pérolas de ebulição. O mercúrio foi adicionado para minimizar a interferência de cloretos, enquanto a prata serve como catalisador da reação.

Os balões com as amostras foram conectados ao condensador de refluxo, permanecendo por 2 horas em refluxo. Após este período, foram adicionados aos balões $150 \mathrm{~mL}$ de água destilada, deixando em repouso até atingir a temperatura ambiente.

As amostras foram tituladas com sulfato ferroso amoniacal $0,25 \mathrm{~N}$ padronizado e indicador ferroin, como auxílio de agitador magnético, até a viragem do verde azulado para o marrom avermelhado, e anotado o volume gasto para os devidos cálculos.

\section{Coliformes}

Para a leitura de coliformes, foram utilizados $100 \mathrm{ml}$ de amostra (diluída ou não). Um nutriente, chamado comercialmente de Colilert, foi adicionado e em seguida a amostra foi distribuída em cartelas que contém vários poços e deixada incubada 24 horas em estufa B.O.D. à $35^{\circ} \mathrm{C}$. Após este período, foi feita a leitura de coliformes totais, comparando-se, com o uso de uma tabela NMP (número mais provável em $100 \mathrm{ml}$ de água), quantos poços da cartela ficaram amarelos. A leitura de coliformes fecais também foi feita pela comparação da mesma tabela com o número de poços amarelos que refletem a luz ultravioleta (GREENBERG; CONNORS; JENKIS, 1992).

\section{Resultados e Discussão}

Nas tabelas de 01 a 05 são apresentados os resultados referentes às análises realizadas entre junho/2004 a novembro/2005, seguindo a quantidade de precipitação pluviométrica na cidade de Londrina, no período estudado (Figura 02).

A alcalinidade das águas subterrâneas, geralmente, situa-se entre 100 e $300 \mathrm{mg} \mathrm{CaCO}_{3} / \mathrm{L}$, somente em casos excepcionais pode atingir $1000 \mathrm{mg} \mathrm{CaCO}_{3} / \mathrm{L}$ (FRANCA et al., 2006). Para o mês de junho, considerado um período seco, a água dos poços revelou variação média de $29,0 \mathrm{mg}$ $\mathrm{CaCO}_{3} / \mathrm{L}$, no Poço 11, e 3581,2mg $\mathrm{CaCO}_{3} / \mathrm{L}$, no Poço 1. No período chuvoso, outubro, alcalinidade foi superior na maioria dos poços, apresentando valores médios entre 26,8 $\mathrm{mg} \mathrm{CaCO}_{3} / \mathrm{L}$ (Poço 8) e 4689,05mg $\mathrm{CaCO}_{3} / \mathrm{L}$ (Poço 1). $\mathrm{O}$ aumento da alcalinidade das águas dos poços, durante esse período, pode estar relacionado à entrada de águas novas devido ao período chuvoso em questão.

As concentrações de coliformes fecais nas águas dos poços apresentaram-se pouco variáveis ao longo do período de monitoramento. Apenas no rio Periquitos houve um índice de 4100 NMP no período chuvoso. Acredita-se que este valor pode ter sido influenciado pela quantidade de animais encontrados próximo a nascente do rio se alimentando.

Por influirem diversos equilibrios químicos que ocorrem naturalmente ou em processos unitários de tratamento de águas, o pH é um parâmetro importante em muitos estudos no campo do saneamento ambiental. A alteração no $\mathrm{pH}$ da água pode resultar em efeitos sobre a fauna, pois a maioria dos peixes não suporta $\mathrm{pH}$ inferiores $\mathrm{a} 5 \mathrm{ou}$ superiores a 9. Há prejuízos ao uso da água na agricultura (o pH apropriado estána faixa de 6-8,5), além do aumento da toxidez de certos compostos, tais como amônia, metais pesados e gás sulfídrico.

Todas as amostras apresentaram-se dentro da faixa de pH prevista na resolução CONAMA 357 de 2005 (BRASIL, 2005), que corresponde a um pH de 6 - 9. Porém os valores de condutividade foram mais elevados em quase todas as amostras. Quando valores de 
Mendes, L. T.; Costa J. S.; França, E.; Teixeira, R.; Lopes, D. D.; Silva, S. M. C. P.; Alves, J. C.; Dall'Antonia, L. H.

condutividade estão acima de $100 \mu \mathrm{S} / \mathrm{cm}$, estes correspondem a ambientes impactados. Somente o Poço 7 (o que se encontra fora da área do aterro) possui valores inferiores a $100 \mu \mathrm{S} / \mathrm{cm}$.

A DBO é um dos parâmetros fundamentais para o controle da poluição das águas por matéria orgânica. Nas águas naturais, a DBO representa a demanda potencial de oxigênio dissolvido que poderá ocorrer devido à estabilização dos compostos orgânicos biodegradáveis, diminuindo os níveis de oxigênio e podendo levar os peixes à morte. É, portanto, importante padrão de classificação das águas naturais. Nas classes que correspondem às águas menos poluídas, exigem-se baixos valores máximos de DBO e elevados limites mínimos de oxigênio dissolvido.

A DQO é um parâmetro indispensável nos estudos de caracterização de esgotos sanitários e de efluentes industriais. ADQOé muitoútil quandoutilizadajuntamente com a DBO para averiguar a biodegradabilidade de despejos. Sabe-se que o poder de oxidação do dicromato de potássio é maior do que a que resulta mediante a ação de microorganismos. Dessa forma, os resultados da DQO de uma amostra são normalmente superiores aos de DBO. Como na DBO mede-se apenas a fração biodegradável. Quanto mais este valor se aproximar da DQO, significa que mais facilmente biodegradável será o efluente.

Os resultados obtidos para o monitoramento dos poços no Aterro Sanitário de Londrina, mostraram valores mais acentuados para os Poços 1 e 2, sendo a região onde estão localizados estes poços aquela de maior contaminação.

Tabela 01 - Resultados das análises de amostras coletadas realizadas em 08/06 2004

\begin{tabular}{|c|c|c|c|c|c|c|c|c|c|c|c|c|}
\hline & & Poço 1 & Poço 2 & Poço 3 & Poço 4 & Poço 5 & Poço 7 & Poço 8 & $\begin{array}{c}\text { Poço } \\
10\end{array}$ & $\begin{array}{c}\text { Poço } \\
11\end{array}$ & $\begin{array}{c}\text { Poço } \\
12\end{array}$ & Rio \\
\hline PARÂMETROS & Unidades & Result. & Result. & Result. & Result. & Result. & Result. & Result. & Result. & Result. & Result. & Result. \\
\hline $\begin{array}{c}\text { Alcalinidade } \\
\text { total }\end{array}$ & $\begin{array}{c}\mathrm{mg} \\
\mathrm{CaCO}_{3} / \mathrm{L}\end{array}$ & 3581,2 & 353,3 & 437,4 & 57 & 170,9 & 43,1 & 46,2 & 238,7 & 29 & 212,5 & 95,5 \\
\hline $\begin{array}{c}\text { Coliformes } \\
\text { Fecais }\end{array}$ & NMP & 0 & 0 & 1 & 0 & 1 & - & 0 & 0 & 0 & 4,1 & 305 \\
\hline $\begin{array}{c}\text { Coliformes } \\
\text { Totais }\end{array}$ & NMP & 2590 & 364 & 172,3 & 3,1 & 85 & 410 & 1616 & 14,5 & 2613 & 74,9 & 16740 \\
\hline Condutividade & $\mu \mathrm{S} / \mathrm{cm}$ & 0,007 & 958 & 1006 & 68 & 397 & 51,7 & 55,4 & 286,4 & 35,1 & 255 & 114,5 \\
\hline Cor & u.c & - & 20 & 10 & 30 & 80 & 5 & 30 & 20 & 40 & 30 & 60 \\
\hline D.B.O. ${ }^{\text {(a) }}$ & $\mathrm{mg} \mathrm{O}_{2} / \mathrm{L}$ & 135 & $<2$ & 2 & $<2$ & $<2$ & $<2$ & 2 & $<2$ & $<2$ & $<2$ & $<2$ \\
\hline D.Q.O. ${ }^{(b)}$ & $\mathrm{mg} \mathrm{O}_{2} / \mathrm{L}$ & 1676,6 & 20,2 & 60,6 & 15,7 & 12,1 & 15,7 & 23,5 & 66,6 & 43,1 & 62,7 & 31,3 \\
\hline $\begin{array}{c}\text { N Total }(\mathrm{NKT}) \\
\text { (c) }\end{array}$ & $\mathrm{mg} \mathrm{N} / \mathrm{L}$ & 850 & 8,96 & 49,3 & 0 & 11,2 & 5,17 & 5,17 & 0 & 5,17 & 1,7 & 6,9 \\
\hline N Amoniacal $^{(\mathrm{d})}$ & $\mathrm{mg} \mathrm{N} / \mathrm{L}$ & 0,234 & 0,073 & 0,076 & 0,074 & 0,075 & 0,079 & 0,158 & 0,182 & 0,154 & 0,158 & 0,132 \\
\hline $\mathrm{pH}$ & - & 7,6 & 6,2 & 6,7 & 5,8 & 6,2 & 5,9 & 6,5 & 6,0 & 5,7 & 6,2 & 7,4 \\
\hline Turbidez & N.T.U & 48,7 & 214 & 3,8 & 371 & 261 & 2,4 & 39,4 & 5,78 & 450 & 14,9 & 10,5 \\
\hline
\end{tabular}

(a) Demanda Bioquímica de Oxigênio

(b) Demanda Química de Oxigênio

(c) Nitrogênio Kjeldahl Total

(d) Nitrogênio Amoniacal 
Aspecto físico-químico e bacteriológico da hidrologia subterrânea na região do depósito de resíduos sólidos urbanos, Londrina, Paraná, Brasil.

Tabela 02 - Resultados das análises de amostras coletadas realizadas em 06/11/2004

\begin{tabular}{|c|c|c|c|c|c|c|c|c|c|c|c|c|}
\hline & & Poço 1 & Poço 2 & Poço 3 & Poço 4 & Poço 5 & Poço 7 & Poço 8 & $\begin{array}{c}\text { Poço } \\
10\end{array}$ & $\begin{array}{c}\text { Poço } \\
11\end{array}$ & $\begin{array}{c}\text { Poço } \\
12\end{array}$ & Rio \\
\hline PARAMETROS & Unidades & Result. & Result. & Result. & Result. & Result. & Result. & Result. & Result. & Result. & Result. & Result. \\
\hline $\begin{array}{c}\text { Alcalinidade } \\
\text { total }\end{array}$ & $\begin{array}{c}\mathrm{mg} \\
\mathrm{CaCO}_{3} / \mathrm{L}\end{array}$ & 4689,05 & 377,3 & 291,06 & 49,28 & 146,3 & 40,04 & 26,18 & 296,05 & 46,2 & 238,75 & 113,96 \\
\hline $\begin{array}{c}\text { Coliformes } \\
\text { Fecais }\end{array}$ & NMP & - & 4 & - & 0 & 0 & 2 & 0 & 0 & - & 0 & 4100 \\
\hline $\begin{array}{l}\text { Coliformes } \\
\text { Totais }\end{array}$ & NMP & - & 60 & - & 81,3 & 8,6 & 1119,9 & 8704 & 547,5 & - & 19863 & 120330 \\
\hline Condutividade & $\mu \mathrm{S} / \mathrm{cm}$ & 10490 & 1113 & 717 & 143,8 & 397 & 96,7 & 117,3 & 1503 & 377 & 970 & 458 \\
\hline Cor & u.c & - & 5 & 10 & 70 & 20 & 5 & $<5$ & 5 & $<5$ & 10 & 20 \\
\hline D.B.O. & $\mathrm{mg} \mathrm{O}_{2} / \mathrm{L}$ & 133 & 3,78 & - & $<2$ & $<2$ & $<2$ & $<2$ & $<2$ & $<2$ & $<2$ & 2,94 \\
\hline D.Q.O. & $\mathrm{mg} \mathrm{O}_{2} / \mathrm{L}$ & 2293,2 & 51 & 27,5 & 4 & 15,7 & 0 & 78,4 & 74,5 & 23,5 & 66,6 & 39,2 \\
\hline $\mathrm{pH}$ & - & 7,8 & 6,6 & 6,6 & 6,1 & 6,2 & 6,1 & 5,8 & 6,1 & 5,8 & 6,5 & 7,3 \\
\hline Turbidez & N.T.U & 36,8 & 8,75 & 20,8 & 197,0 & 15,1 & 14,7 & 2,75 & 1,17 & 5,15 & 3,35 & 4,66 \\
\hline
\end{tabular}

Tabela 03 - Resultados das análises de amostras coletadas realizadas em 11/07/2005

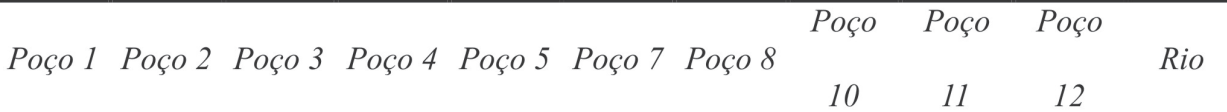

PARÂMETROS Unidades Result. Result. Result. Result. Result. Result. Result. Result. Result. Result. Result.

\begin{tabular}{|c|c|c|c|c|c|c|c|c|c|c|c|c|}
\hline Condutividade & $\mu \mathrm{S} / \mathrm{cm}$ & 5,8 & 732,0 & 583,0 & - & 278,0 & - & 153,5 & 1514,3 & 280,0 & 867,0 & 619,0 \\
\hline D.Q.O. & $\mathrm{mg} \mathrm{O}_{2} / \mathrm{L}$ & & & & - & 43,1 & - & & & & & 39,2 \\
\hline & & 1235,3 & 58,8 & 39,2 & & & & 31,4 & 192,2 & 43,1 & 82,4 & \\
\hline $\mathrm{pH}$ & - & & & & - & 6,1 & - & 6,5 & 6,1 & 5,6 & 6,1 & 6,7 \\
\hline Turbidez & N.T.U & $\begin{array}{c}7,4 \\
16,3\end{array}$ & $\begin{array}{l}6,1 \\
6,2\end{array}$ & $\begin{array}{l}6,5 \\
3,2\end{array}$ & - & 2,6 & - & 1,0 & 9,4 & 1,3 & 4,3 & 8,9 \\
\hline
\end{tabular}

Tabela 04 - Resultados das análises de amostras coletadas realizadas em 30/08/2005

Poço 1 Poço 2 Poço 3 Poço 4 Poço 5 Poço 7 Poço $8 \begin{array}{ccccc}\text { Poço } & \text { Poço } & \text { Poço } & \text { Rio } \\ 10 & 11 & 12 & \end{array}$

PARÂMETROS Unidades Result. Result. Result. Result. Result. Result. Result. Result. Result. Result. Result.

\begin{tabular}{ccccccccccccc}
\hline Condutividade & $\mu \mathrm{S} / \mathrm{cm}$ & 6,0 & 700,0 & 505,0 & & 167,3 & 152,4 & 1356,0 & 269,0 & 839,0 & 469,0 & 6,0 \\
D.B.O. & $\mathrm{mg} \mathrm{O}_{2} / \mathrm{L}$ & 0,7 & - & 0,5 & 0,7 & & 0,2 & 0,4 & 1,1 & 2,5 & 1,2 & 0,7 \\
D.Q.O. & $\mathrm{mg} \mathrm{O}_{2} / \mathrm{L}$ & 1120,0 & 36,0 & 24,0 & & 8,0 & 12,0 & 136,0 & 24,0 & 80,0 & 28,0 & 1120,0 \\
N Total (NKT) & $\mathrm{mg} \mathrm{N} / \mathrm{L}$ & 850 & 8,96 & 49,3 & 0 & 11,2 & 5,17 & 5,17 & 0 & 5,17 & 1,7 & 6,9 \\
N Amoniacal & $\mathrm{mg} \mathrm{N} / \mathrm{L}$ & 0,234 & 0,073 & 0,076 & 0,074 & 0,075 & 0,079 & 0,158 & 0,182 & 0,154 & 0,158 & 0,132 \\
pH & - & 7,4 & 6,0 & 6,5 & & 6,0 & 5,9 & 6,2 & 5,7 & 6,0 & 6,1 & 7,4 \\
Turbidez & N.T.U & 8,1 & 5,4 & 6,8 & & 1,4 & 3,5 & 1,5 & 2,2 & 2,7 & 0,3 & 8,1 \\
\hline
\end{tabular}


Mendes, L. T.; Costa J. S.; França, E.; Teixeira, R.; Lopes, D. D.; Silva, S. M. C. P.; Alves, J. C.; Dall'Antonia, L. H.

Tabela 05 - Resultados das análises de amostras coletadas realizadas em 14/11/2005

\begin{tabular}{|c|c|c|c|c|c|c|c|c|c|c|c|c|}
\hline & & Poço 1 & Poço 2 & Poço 3 & Poço 4 & Poço 5 & Poço 7 & Poço 8 & $\begin{array}{c}\text { Poço } \\
10\end{array}$ & $\begin{array}{c}\text { Poço } \\
11\end{array}$ & $\begin{array}{c}\text { Poço } \\
12\end{array}$ & Rio \\
\hline PARÂMETROS & Unidades & Result. & Result. & Result. & Result. & Result. & Result. & Result. & Result. & Result. & Result. & Result. \\
\hline Condutividade & & 5,5 & 1574,0 & 776,0 & 135,5 & 253,0 & - & 117,6 & 1480,0 & 254,0 & 1050,0 & 295,0 \\
\hline & - & 7,4 & 6,1 & 6,6 & 6,1 & 6,4 & - & 5,9 & 6,2 & 6,0 & 6,1 & 6,3 \\
\hline dez & N.1. & 7,0 & 0,5 & 0,6 & $\gg 10$ & 2,6 & - & 1,0 & 1,8 & 5,5 & 3,1 & 0,4 \\
\hline
\end{tabular}

\section{Conclusões}

O poço 1, como mostrado pela tabela dos parâmetros, é sem dúvida o mais poluído, pois em todas as análises realizadas obtém-se resultados fora dos padrões de qualidade de água. O poço 1 possui 28 metros de profundidade e o nível de água se encontra a $15 \mathrm{~m}$, e isso pode indicar o tamanho de sua poluição.

O prazo de funcionamento desse aterro de resíduos sólidos está praticamente esgotado, devido à capacidade de receber resíduos deste local já ter quase ultrapassado seu limite. Escolher uma nova área para um aterro contribuiria para a elevação da qualidade de vida da cidade de Londrina.

\section{Referência}

\section{COMPANHIA DE TECNOLOGIA E} SANEAMENTO AMBIENTAL - CETESB. Relatório de estabelecimento de valores orientadores para solos e águas subterrâneas no estado de São Paulo.São Paulo, 2001.

IBGE. Censo demográfico 2000. Disponível em: <http://www.ibge.gov.br/cidadesat/default.php>. Acesso em: 21 de ago. 2006.
BRASIL. Ministério de Desenvolvimento Urbano e Meio Ambiente. Conselho Nacional do Meio Ambiente-CONAMA. Resolução no 357 de 17 de março de 2005. Dispõe sobre a classificação dos corpos de água e diretrizes ambientais para o seu enquadramento, bem como estabelece as condições e padrões de lançamento de efluentes, e dá outras providências. Disponível em: <http://72.14.253.104/ search?q=cache:FkZnGkOHNOoJ:www.cetesb.sp.gov.br/ Agua/praias res_conama_357_05.pdf+\%22conama $\% 22 \& \mathrm{hl}=\mathrm{pt}-\mathrm{BR} \& \mathrm{ct}=\mathrm{clnk} \& \mathrm{~cd}=4 \& \mathrm{gl}=\mathrm{br}>$.

Acesso em: 21 ago. 2006.

FRANCA, R. M.; FRISCHKORN, H.; SANTOS, M. R. P.; MENDONÇA, L. A. R.; BESERRA, M. C. Contaminação de poços tubulares em Juazeiro do Norte-CE. Engenharia Sanitária e Ambiental, Rio de Janeiro, v.11, n.1, p.92-102, jan./mar. 2006.

GREENBERG, A. E.; CONNORS, J. J.; JENKIS, D. Standard methods for the examination of water and wastewater. New York: APHA, 1992.

VON SPERLING, M. Introdução à qualidade das águas e ao tratamento de esgotos. 2 ed. Belo Horizonte: Departamento de Engenharia Sanitária e Ambiental - UFMG, 1996. 